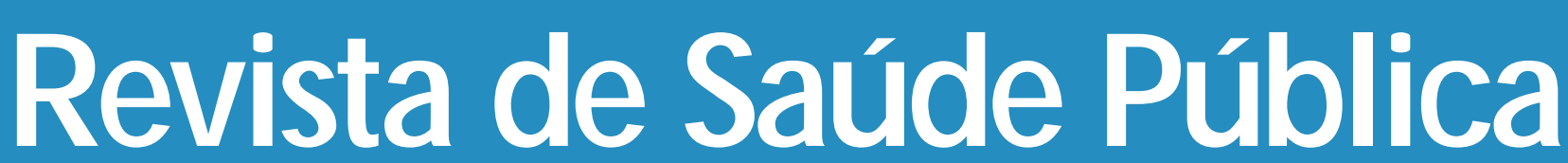

$\begin{array}{lllllll}J & 0 & \mathbf{U} & \mathbf{R} & \mathbf{N} & \mathbf{A} & \mathbf{L}\end{array}$

$0 F$

$\mathbf{P} \mathbf{U}$

B L I C

H E A L T

\title{
Novos encontros de anofelíneos em recipientes artificiais*
}

\section{New findings of Anopheles mosquitoes in artificial containers}

O swaldo Paulo Forattini, Iná Kakitani, G isela Rita Alvarenga Monteiro Marques e Marylene de Brito

Departamento de Epidemiologia da Faculdade de Saúde Pública da U niversidade de São Paulo. São Paulo, SP - Brasil (O.P.F., I.K.), Superintendência de Controle de Endemias. Taubaté, SP - Brasil (G.R.A. M.M., M.B.)

FO RATTIN I 0 swaldo Paulo, Iná Kakitani, G isela Rita Alvarenga Monteiro Marques e Marylene de Brito Novos encontros de anofelíneos em recipientes artificiais* Rev. Saúde Pública, 32 (6): 598-9, 1998

(c) Copyright Faculdade de Saúde Pública da USP. Proibida a reprodução mesmo que parcial sem a devida autorização do Editor Científico. Proibida a utilização de matérias para fins comerciais. All rights reserved. 


\title{
Novos encontros de anofelíneos em recipientes artificiais*
}

\section{New findings of Anopheles mosquitoes in artificial containers}

\author{
O swaldo Paulo Forattini, Iná Kakitani, G isela Rita Alvarenga Monteiro Marques \\ e Marylene de Brito \\ Departamento de Epidemiologia da Faculdade de Saúde Pública da Universidade de São Paulo. São \\ Paulo, SP - Brasil (O.P.F., I.K.), Superintendência de Controle de Endemias. Taubaté, SP - Brasil \\ (G.R.A.M.M., M.B.)
}

\begin{abstract}
Resumo
Assinalam-se novos encontros de anofelíneos em recipientes artificiais. Um deles diz respeito a formas imaturas de Anopheles bellator em criadouros experimentais e outro é concernente ao achado de An. albitarsis l.s., em recipiente abandonado. Tecem-se considerações sobre a pressão seletiva representada pela produção, cada vez maior, de objetos descartáveis.
\end{abstract}

Anopheles. Larva.

\begin{abstract}
New findings of Anopheles mosquitoes in artificial containers are reported. In one, a plastic container served as a breeding place for Anopheles bellator larvae and, in another, four instar larvae of An. albitarsis s.l. were found in an abandoned toilet basin. Reflections are offered as to the selective pressure represented by the production, of an ever increasing scale, of disposable objects.
\end{abstract}

Anopheles. Larva.

*Pesquisa subvencionada pela Fundação de Amparo à Pesquisa do Estado de São Paulo/FAPESP (Processo Temático $n^{\circ}$ 95/0381-4) e pelo Conselho Nacional de Desenvolvimento Científico e Tecnológico/CNPq (Bolsa de Produtividade em Pesquisa-Processo ${ }^{\circ}$. 3000225/95-4).

Correspondência para/Correspondence to: Oswaldo Paulo Forattini - Núcleo de Pesquisa Taxonômica e Sistemática em Entomologia Médica/

NUPTEM - Av. Dr. Arnaldo, 715- 01246-904 São Paulo, SP - Brasil. E-mail: opforati@usp.br

Edição subvencionada pela FAPESP (Processo n ${ }^{\circ}$ 97/09815-2).

Recebido em 11.9.1998. Aprovado em 15.9.1998. 
De maneira geral e no estado atual dos conhecimentos nas Américas, considera-se como anômalo o encontro de formas imaturas de Anopheles criando-se em recipientes artificiais, fora do ambiente de laboratório. Em vista disso, o registro de tais encontros reveste-se de significado epidemiológico a ser considerado.

Em relação a Anopheles bellator, aos dados anteriormente relatados (Forattini e col. ${ }^{1}, 1998$ ), caberá acrescentar os que se seguem. Dos criadouros experimentais instalados na localidade de Pedrinhas, Município de Ilha Comprida, e descritos naquela ocasião, a caixa d'água forneceu mais duas larvas. Estas foram coletadas nas inspecções levadas a efeito nos dias 23/4/98 e 5/5/ 98. Tais larvas eram de $2^{\circ}$ estádio, as quais, em condições de laboratório, deram origem a dois machos, decorridos 14 e 16 dias, respectivamente. Juntamente com elas foram coletadas 122 formas de Aedes albopictus, somados os dados referentes às duas coletas. Ainda no que concerne aos criadouros experimentais, foram instalados recipientes de plástico considerados de tamanho médio e compreendendo volume correspondente a 10 litros de água. Nas inspecções levadas a efeito, naquelas mesmas datas, pôde-se encontrar, em dois deles, uma larva de $2^{\circ}$ estádio e uma larva de $1^{\circ}$, respectivamente levadas ao laboratório; aquela morreu como pupa masculina, após 17 dias, e esta, decorrido o período de 25 dias, deu origem a um exemplar do mesmo sexo. No primeiro recipiente figuravam 78 formas imaturas de Ae. albopictus. No segundo, além da referida larva pôde-se coletar as seguintes formas imaturas:
Ae. albopictus, 3
Cx. quinquefasciatus, 164
Culex corniger, 51
Cx. reducens, 11

Outras duas observações puderam ser feitas durante a execução de projeto destinado a estimar a produtividade de criadouros artificiais. Para tanto, adotou-se metodologia baseada no uso de rede ("sweep net") e implicando a coleta de espécimens representados somente por larvas de $4^{\circ}$ estádio e pupas (Tun-Lin e col. ${ }^{3}$, 1994). O local onde foram feitas as observações foi o denominado Chácara da Manoela, propriedade rural de pequeno porte com, aproximadamente, $6.000 \mathrm{~m}^{2}$, localizada na região periurbana do Município de Tremembé, no Vale do Paraíba, Estado de São Paulo, Brasil. Tratase de local precipuamente destinado ao lazer e, talvez, por esse motivo, o terreno apresenta cobertura vegetal do tipo frutífera e diversificada. O sítio dista, em linha reta, cerca de meio quilômetro da várzea do Rio Paraíba que corre no vale e onde há cultivo de arroz. Na primeira coleta efetuada no dia 28/4/98 foi possível obter 9 larvas de $4^{\circ}$ estádio, identificadas como sendo de Anopheles albitarsis 1.s. O criadouro foi representado por pia abandonada, na ocasião, portando cerca de 20 litros de água (Fig.). A segunda refere-se à obtenção de mais 9 larvas, também iden-tificadas como sendo da mesma espécie, coletadas quando da inspeção realizada no dia 29/9/98, em criadouro experimental de plástico, ali instalado e classificado como sendo de porte médio, contendo 10 litros de água. Juntamente com essas formas imaturas, pôde-se conseguir as seguintes:

$\begin{array}{lll} & \text { Pia } & \text { Balde plástico } \\ \text { Ae. albopictus } & 7 \text { larvas } & \text { 18 larvas e 21 pupas } \\ \text { Li. durhami } & 5 \text { larvas } & - \\ \text { Cx quinquefasciastus } & - & \text { 22 larvas }\end{array}$

Tais encontros regionais, evidenciando alterações na escolha de habitats para desenvolvimento de formas imaturas de Culicidae e a exemplo de relatos anteriores (Forattini e col ${ }^{1,2}$., 1997, 1998), parecem resultar do processo de pressão seletiva, consequiente do atual estádio cultural da sociedade humana. E isso traduzindose pela excessiva produção de recipientes descartáveis, acrescida pela de grande número de implementos e objetos de transitoriedade cada vez maior. Daí a grande oferta de locais potencialmente utilizáveis como locais de criação de mosquitos. É de se admitir que esse fator deva ser levado em consideração nas práticas de vigilância epidemiológica.

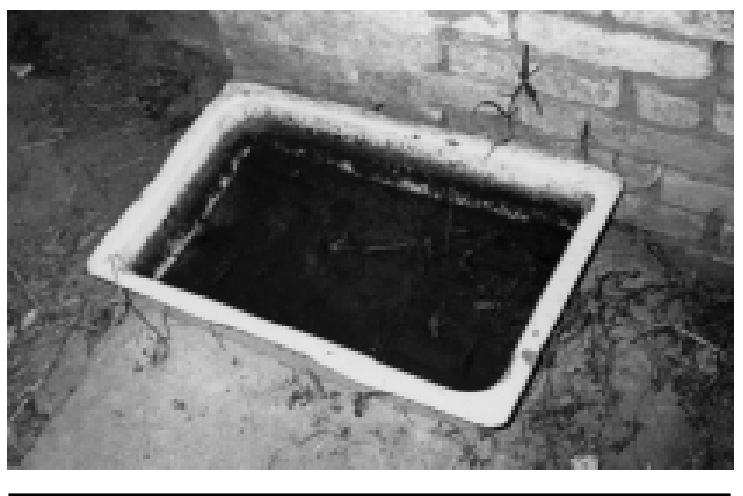

Figura - Aspecto do recipiente representado por pia abandonada na qual foram encontradas formas imaturas de An. albitarsisl.s.

\section{REFERÊNCIAS}

1. FORATTINI, O.P.; KAKITANI, I.; SALLUM, M.A.M Encontro de criadouros de Aedes scapularis (Diptera: Culicidae) em recipientes artificiais. Rev. Saúde Pública, 31:519-22, 1997.

2. FORATTINI, O.P.; KAKITANI, I.; MARQUES, G.R.A.M.; BRITO, M. de. Formas imaturas de anofelíneos em recipientes artificiais. Rev. Saúde Pública, 32:189-91, 1998.

3. TUN-LIN, W.; KAY, B.H.; BURKOT, T.R. Quantitative sampling of immature Aedes aegypti in metal drums using sweep net and dipping methods. J. Am. Mosq. Control Assoc., 10:390-6, 1994. 